\title{
QUESTÕES DE LOCALIZAÇÃO E CONECTIVIDADE NA AVALIAÇÃO DE QUALIDADE URBANA EM EMPREENDIMENTOS DE HABITAÇÃO DE INTERESSE SOCIAL EM INDAIATUBA
}

\section{LOCATION AND CONNECTIVITY MATTERS TO ASSESS URBAN QUALITY IN INDAIATUBA'S SOCIAL HOUSING PROGRAMS}

\author{
Eloisa Dezen-Kempter ${ }^{1}$ \\ Universidade Estadual de Campinas, Limeira, SP, Brasil, elo@ft.unicamp.br \\ Juliana Camargo Anhaia ${ }^{2}$ \\ Universidade Estadual de Campinas, Limeira, SP, Brasil, juliana.anhaia@uol.com.br \\ Luan de Oliveira Terra ${ }^{3}$ \\ Universidade Estadual de Campinas, Limeira, SP, Brasil, luan_lot@yahoo.com.br
}

\section{Resumo}

O processo de urbanização brasileiro foi historicamente marcado pela desigualdade socioespacial, perceptível na implantação de empreendimentos habitacionais de interesse social (EHIS) em zonas desprovidas de infraestrutura e serviços urbanos. Com o intuito de analisar como a problemática da segregação socioespacial, definidas por fatores locacionais e de acesso aos equipamentos e infraestruturas urbanas, afetam a qualidade urbana e a percepção do lugar por parte do usuário, este artigo apresenta um estudo realizado em três empreendimentos habitacionais de interesse social (EHIS) no município de Indaiatuba (SP), implantados sob diferentes políticas de desenvolvimento urbano. Com o objetivo de contextualizar os estudos de caso, foi realizada uma análise dos planos diretores de Indaiatuba sob a ótica do zoneamento e produção habitacional de interesse social. Na realização desta pesquisa foram utilizadas técnicas de avaliação pós-ocupação (APO), com a aplicação de questionários estruturados no formato de entrevistas presenciais, assim como, registros em campo por meio de levantamentos fotográficos, visando aferir o nível de satisfação dos moradores em relação aos aspectos de localização e conectividade. Verificou-se que o desenvolvimento de atividades sociais urbanas e os espaços públicos disponíveis para essas práticas influenciam a visão que os moradores têm de seu bairro, portanto questões relativas à conectividade assumem um papel fundamental na construção dessa imagem. A contribuição deste trabalho está na correlação entre as características avaliadas na APO e as diretrizes apresentadas nos planos diretores, de modo que a APO possa ser um balizador para correção e direcionamento das proposições dos próximos instrumentos de desenvolvimento urbano.

Palavras-chave: Habitação de Interesse Social. Qualidade Urbana. Avaliação pós-ocupação. Localização. Conectividade.

\begin{abstract}
The urbanization process of Brazilian cities has been marked, historically, by socio-spatial inequality. Spatial segregation occurs mainly in the housing field, in that social housing programs are placed in areas devoiding of infrastructure and urban services. The purpose of this study was to investigate how the socio-spatial segregation issue, defined in terms of location, connectivity and access to urban equipment and infrastructure, influences the urban quality and the resident site perception. Thus, the study was conducted in three social housing projects in Indaiatuba (SP), launched on different urban development policies. In order to contextualize the case studies, a review of the Indaiatuba master plans was made, focused on zoning and social housing policies. In this research, post-occupancy evaluation (POE) techniques were use, applying structured questionnaires in form of in-person interviews, as well as, in situ surveys using pictures, in order to measure the dwellers' satisfaction level in the aspects of location and connectivity. The paper concludes that the residents' vision on their neighborhood is influenced by the development of urban social activities and the availability of public spaces for those practice, thus, issues related to connectivity play a key role to build this vision. As a contribution, this paper present a critical analysis of the POE results interlinked with the master plans guidelines, in order to benefit the further urban development strategies.
\end{abstract}

Keywords: Social Housing Program. Urban Quality. Post-occupancy evaluation. Location. Connectivity.

How to cite this article:

DEZEN-KEMPTER, Eloisa; ANHAIA, Juliana C.; TERRA, Luan O. Questões de localização e conectividade na avaliação de qualidade urbana de habitação de interesse social em Indaiatuba. PARC Pesquisa em Arquitetura e Construção, Campinas, SP, v. 6, n. 3, p. 155-168, set. 2015. ISSN 1980-6809. Disponível em: <http://periodicos.sbu.unicamp.br/ojs/index.php/parc/article/view/8635020>. Acesso em: 09 mar. 2016. doi:http://dx.doi.org/10.20396/parc.v6i3.8635020.

Introdução 
No Brasil, um longo caminho de políticas urbanas, voltadas para a habitação de interesse social (HIS), conduziram sua implantação de forma segregada, em zonas com baixa provisão de equipamentos e serviços urbanos, em um cenário que compromete a função social da habitação relacionada às oportunidades que os indivíduos têm para realizar suas atividades cotidianas e aquelas que promovem seu desenvolvimento pessoal.

Os modelos de produção de HIS adotados no Brasil promoveram o agravamento do processo de periferização, demandando enormes investimentos de infraestrutura e potencializando os problemas de deslocamento e vulnerabilidade social (ROLNIK et al., 2010).

Mesmo no modelo atual, o Programa Minha Casa Minha Vida (PMCMV), problemas relacionados ao planejamento urbano, à qualidade arquitetônica e urbanística, e questões de infraestruturas urbanas continuaram intocadas, como nos modelos anteriores (ROLNIK; NAKANO, 2009; NASCIMENTO; TOSTES, 2011).

Considerando-se que a tipologia habitacional ocupa um percentual significativo da malha urbana, percebe-se que a ausência de uma abordagem urbanística no planejamento de HIS favorece a ocupação do solo de forma desordenada e desenfreada. Estruturalmente e historicamente, a população de baixa renda foi espacialmente discriminada, sujeita ao capital imobiliário e colocada aquém de questões sociais, de integração e de qualidade de vida.

O Plano Diretor Municipal, a partir da constituição de 1988 e da promulgação do Estatuto da Cidade, adquiriu a função de principal instrumento de política urbana, incorporando novos instrumentos urbanísticos voltados para induzir formas de uso e ocupação do solo menos excludentes (ROLNIK et al., 2010).

Pesquisas no âmbito da inserção urbana e avaliação pósocupação (APO) têm sido realizadas por programas como o HABITARE, visando aferir a forma como as HIS se inserem no espaço urbano contínuo, o provimento de infraestrutura e de equipamentos e serviços urbanos. (WERNA et al, 2001; ABIKO; ORNSTEIN, 2002).

Segundo Roméro e Ornstein (2003), APO é um instrumento eficaz para efetuar diagnósticos que subsidiem recomendações e diretrizes (funcionais, operacionais, de desempenho) para a melhoria das condições existentes, ou visando projetos futuros.

Ainda de acordo com os mesmos autores, a relevância da APO em programas habitacionais de interesse social justifica-se pois,

[...] nas últimas décadas, têm-se adotado soluções urbanísticas, arquitetônicas e construtivas repetitivas em larga escala, para atender uma população, via de regra, muito heterogênea, cujo repertório cultural, hábitos, atitudes e crenças são bastante distintos (ROMÉRO; ORNSTEIN, 2003, p.27).

Assiste-se ao crescimento considerável do número de estudos baseados em APO aplicados a empreendimentos habitacionais de interesse social (EHIS) (ABIKO; ORNSTEIN, 2002; KOWALTOWSKI et al, 2006; KOWALTOWSKI; GRANJA, 2011; CONCEIÇÃO; IMAI; URBANO, 2015). O foco da APO destas pesquisas concentra-se principalmente no produto habitacional e no processo de provisão de HIS. Destas pesquisas pode-se concluir que as políticas habitacionais baseadas em quantidade ao invés de qualidade precisam ser revistas.

Werna, Abiko e Coelho (2002) investigaram o produto habitacional em seis EHIS na região metropolitana de São Paulo, a partir de aplicação de APO, e concluíram que o desempenho de questões como acessibilidade, saúde, educação, segurança, lazer, transporte, localização de EHIS influenciam diretamente a boa qualidade de vida de seus usuários, assim como os conceitos que estes atribuem à unidade habitacional, ao conjunto e ao entorno.

Elali (2006) destaca o caráter trans- e multidisciplinar do trabalho de APO, enfatizando que aspectos funcionais e comportamentais, este último na perspectiva da psicologia ambiental, têm grande potencial para amparar decisões de projeto (arquitetônico e urbanístico) mais adequadas às expectativas dos usuários.

Quanto às variáveis associadas aos atributos ambientais, Lynch (1999) afirma que a avaliação destes atributos, e sua ênfase ou desprezo por parte do observador, está associada aos valores socioculturais e características socioeconômicas do grupo analisado. Portanto, a partir das respostas dos moradores pode-se aferir a capacidade do ambiente em atender às necessidades básicas relativas à funcionalidade, segurança, saúde, socialização, que constituem a imagem coletiva do bairro, que quando favorável proporciona uma relação harmoniosa do morador com seu ambiente.

Este artigo apresenta uma breve análise do desenvolvimento urbano da cidade de Indaiatuba, através da ótica de seus planos diretores, visando identificar diretrizes de implantação de EHIS e relacionar a política urbana municipal e a problemática da localização. Na sequência, apresenta os 3 estudos de caso, e a metodologia usada para aferir o nível de satisfação dos moradores com os serviços urbanos existentes no bairro. Na discussão apresenta os resultados da APO, e a relevância de questões de localização e conectividade na análise de qualidade urbana.

\section{O Município de Indaiatuba}

Indaiatuba é um dos 19 municípios que compõem a Região Metropolitana de Campinas, criada em 2000, e possui 
aproximadamente 220 mil habitantes (SEADE, 2015). O processo de descentralização industrial da Região Metropolitana de São Paulo, a partir da década de 1970, foi um dos propulsores do incremento habitacional da cidade, mais que triplicando a sua população entre as décadas de 1970-1991 e reduzindo significativamente a população rural da cidade (Figura 1).

Figura 1 - Evolução da População Total, Urbana, e o grau de urbanização entre as décadas de 1970-2010, baseado nos censos do IBGE

\section{EVOLUÇĀO POPULACIONAL (1970-2010)}

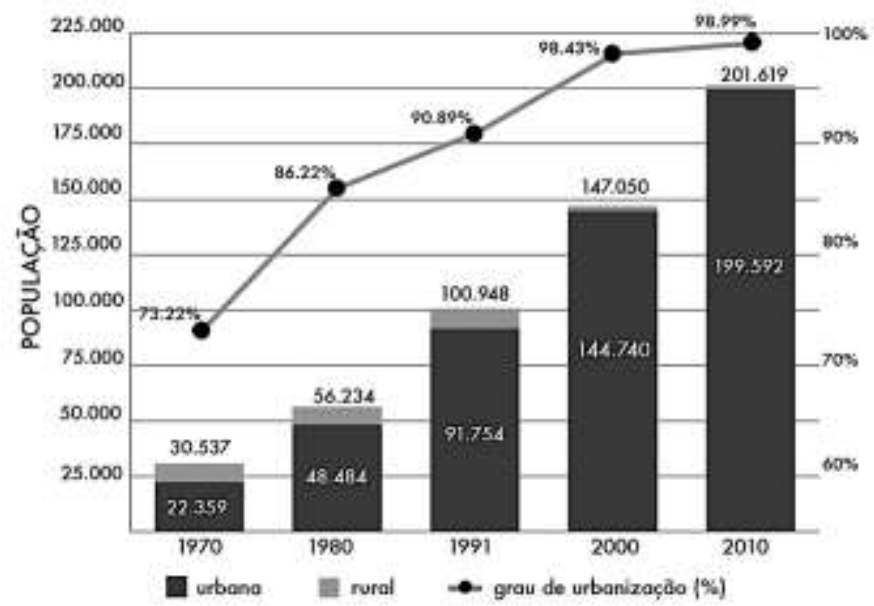

Fonte: Os autores

Analisando o seu saldo migratório no período de 1970 a 2000 (Tabela 1), verifica-se que este se mantém crescente comparado com o da Região Metropolitana de Campinas, que apresenta um acentuado decréscimo.

Tabela 1 -Saldos migratórios e participação da migração no crescimento absoluto da população de Indaiatuba e da Região Metropolitana de Campinas entre 1970-2000

\begin{tabular}{lcccccc} 
& \multicolumn{3}{c}{ Saldo Migratório } & \multicolumn{3}{c}{$\begin{array}{c}\text { Participação da } \\
\text { migração (\%) }\end{array}$} \\
\cline { 2 - 7 } & $1970-$ & $1980-$ & $1991-$ & $1970-$ & $1980-$ & $1991-$ \\
Período & 1980 & 1991 & 2000 & 1980 & 1991 & 2000 \\
\hline Indaiatuba & 18.598 & 29.380 & 30.943 & 72,37 & 65,91 & 85 \\
\hline RMC & 356.171 & 279.438 & 189.660 & 59,77 & 47,62 & 42 \\
\hline
\end{tabular}

Fonte: Adaptado de Baeninger (2001, p. 332), Alves (2002, p.318)

O crescimento da cidade de Indaiatuba também pode ser avaliado através da direção da expansão urbana metropolitana de Campinas, desenvolvido por Caiado e Pires (2006). Segundo os autores, podem ser identificados na RMC 8 vetores de expansão, 7 acompanhando os principais eixos rodoviários e o último dentro do próprio centro metropolitano (Figura 2).

$\mathrm{O}$ vetor 7 é o de expansão em direção à Indaiatuba, seguindo a Rodovia SP-75 Santos Dumont (Rodovia José Ermínio de Moraes) no sentido da RM de Sorocaba. Essa direção apresenta uma concentração fabril de importância regional, iniciada nos anos de 1930-40, e um centro de comércio e serviços dinâmico. Apresenta ainda grande potencial de crescimento de atividades econômicas, devido à localização do Aeroporto de Viracopos, projetado para ser o maior centro cargueiro da América Latina, e sua articulação com as principais Rodovias do Estado Anhanguera, Bandeirantes, Castelo Branco e Raposo Tavares (CAIADO; PIRES, 2006). Os autores ainda sugerem que o processo de ampliação do aeroporto de Viracopos limitou a abertura de novos loteamentos na sua área de influência, impedindo que o processo de conurbação e a continuidade do padrão de loteamentos precários e favelas existentes em Campinas se espraiasse além da divisa com a cidade. Pelo contrário, a implantação de habitação para a população de baixa renda concentrouse na direção sudoeste da cidade, oposta à divisa com Campinas, acomodada em áreas de urbanização formal, sem a presença de favelas (CAIADO; PIRES, 2006).

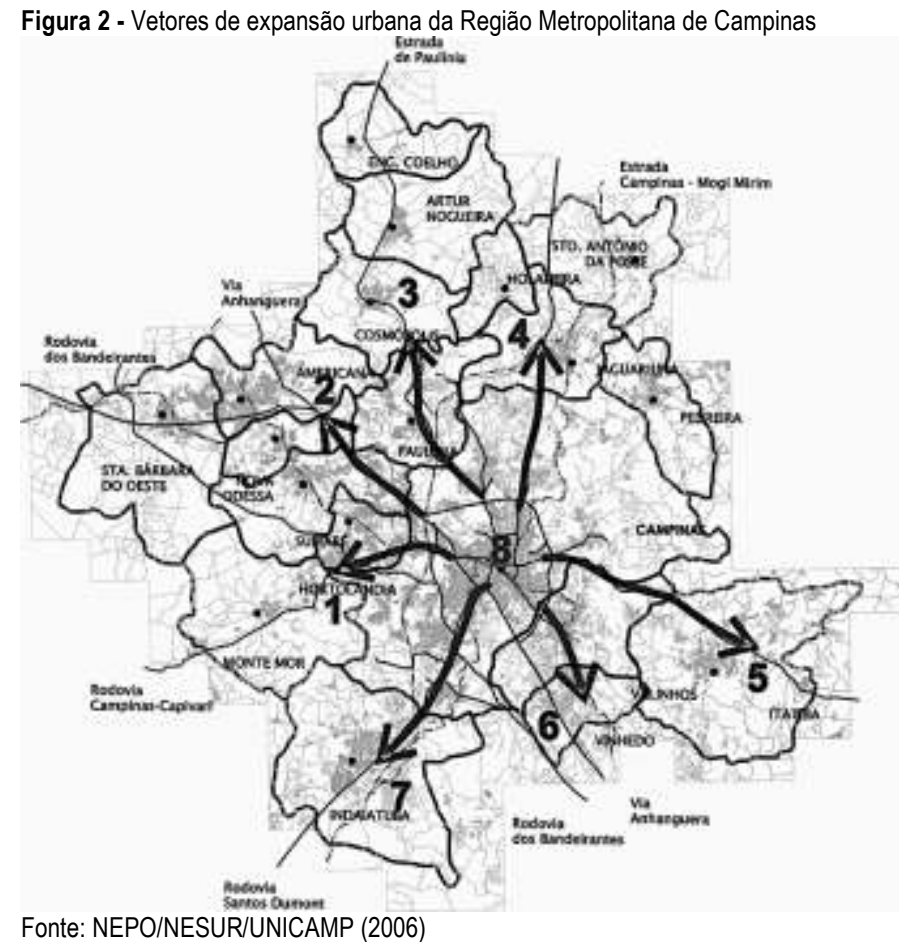

Considerando esses fatores e outros indicadores como longevidade (saúde), renda e educação, Indaiatuba apresenta um Índice de desenvolvimento humano (IDH) alto, 0.788, segundo o Programa das Nações Unidas para o Desenvolvimento (BRASIL, 2013), acima do IDH do estado de São Paulo que é 0,783 .

\section{A questão de localização urbana nos planos diretores de Indaiatuba}

O Plano Diretor é o instrumento básico da política urbana municipal, conforme a Constituição Federal de 1988, que influencia diretamente o desenvolvimento das cidades brasileiras.

O zoneamento é peça fundamental do Plano Diretor e permite caracterizar o solo em zonas diferenciadas, para as 
quais são aplicados parâmetros de uso e ocupação específicos. Contudo, quando mal utilizado, o zoneamento serviria como instrumento de segregação social à medida que demarca zonas nas quais a ocupação tende a ser composta por grupos homogêneos, aumentando a desigualdade urbana (SABOYA, 2007).

$\mathrm{O}$ zoneamento de Indaiatuba dividiu a cidade em uma zona central bem-dotada de infraestrutura urbana e equipamentos públicos, com benefícios locacionais para a população de alta renda, que ora se encontra no entorno imediato, ou não depende do transporte público para acessar esses serviços. Por outro lado, impôs para a população de baixa renda uma localização mais periférica, desprovida de urbanização inclusiva, com poucos equipamentos e serviços urbanos, impulsionando a segregação socioespacial.

Esse padrão pode ser percebido nos quatro planos diretores da cidade: 1968, 1990, 2001 e 2010. Os dois últimos planos, concebidos dentro dos preâmbulos do Estatuto das Cidades (Lei Federal N.10.257/2001) representam o interesse dos munícipes, votado e aprovado pela Câmara dos vereadores.

\section{Primeiro plano diretor de Indaiatuba (1968)}

Desenvolvido pelo Arquiteto Jorge Wilheim, o plano denominado "Plano de Desenvolvimento Integrado", direcionou a expansão urbana até a década de 80, em um período marcado pelo crescimento acelerado e grande fluxo migratório para a cidade. A legislação urbana decorrente deste plano (Lei N.1048/1969) delimitou o perímetro urbano que se expandia com o crescimento econômico e demográfico do Município. Esse crescimento ultrapassou os limites de expansão impostos no plano, ocasionando o crescimento desordenado de áreas como a zona sul, com a instalação da população sem planejamento e organização urbana, afetando o sistema viário da cidade, fazendo-se necessário normatizar os loteamentos e a construção de casas populares. O plano previa como vetor de expansão urbana "[...] o quadrante Noroeste, tendo por eixo e vetor a atual estrada de Monte Mor" (INDAIATUBA, 1968, p. 113). É neste período também que é criado o distrito industrial e a administração municipal promulga uma série de leis de incentivos para estimular a ampliação de seu parque industrial. Juntamente com as indústrias que se estabelecem neste período em Indaiatuba, verifica-se o crescimento do saldo migratório (conforme destacado na Tabela 1) e da demanda por habitação popular.

A política habitacional brasileira, no momento que este plano é desenvolvido, caracterizava-se pela atuação do Banco Nacional de Habitação (BNH), cujo objetivo era garantir o direito de construção através de financiamento da casa própria para a população de menor renda. Segundo
Medeiros (2010), a principal crítica ao BNH é o abandono da questão social em detrimento de seu desenvolvimento econômico como financiador de obras. Outra crítica ao $\mathrm{BNH}$ é relativa à baixa qualidade arquitetônica e urbana da habitação oferecida para a população de baixa renda, em função da excessiva padronização dos projetos, dimensão dos conjuntos, localização na franja periférica, execução precária, ausência de participação do usuário e financiamento inacessível às faixas de menor renda (NASCIMENTO; BRAGA, 2009).

Efeitos desta política podem ser percebidos na implantação do loteamento popular Jardim Morada do Sol (1980), motivado, dentre outros aspectos, pelo grande contingente de trabalhadores vindos do Paraná para Indaiatuba para trabalhar na indústria. Na década de 1980, os paranaenses correspondiam a quase $20 \%$ do saldo da população migrante da cidade. O Jardim Morada do Sol, conhecido como cidade nova, tornou-se o maior bairro do município com cerca de 8,8 mil residências e 44 mil habitantes (ALVES, 2002).

A Figura 3 apresenta a situação urbana de Indaiatuba no final da década de 1990, com destaque para o Bairro Morada do Sol, contíguo à zona industrial (quadrante sudoeste).

Figura 3 - Comparação entre as áreas urbanizadas e o limite do perímetro urbano de Indaiatuba no final da década de 1980 e a situação atual. Destaca-se a área ocupada pelo Bairro Morada do Sol, e a delimitação do então inexistente Parque Ecológico

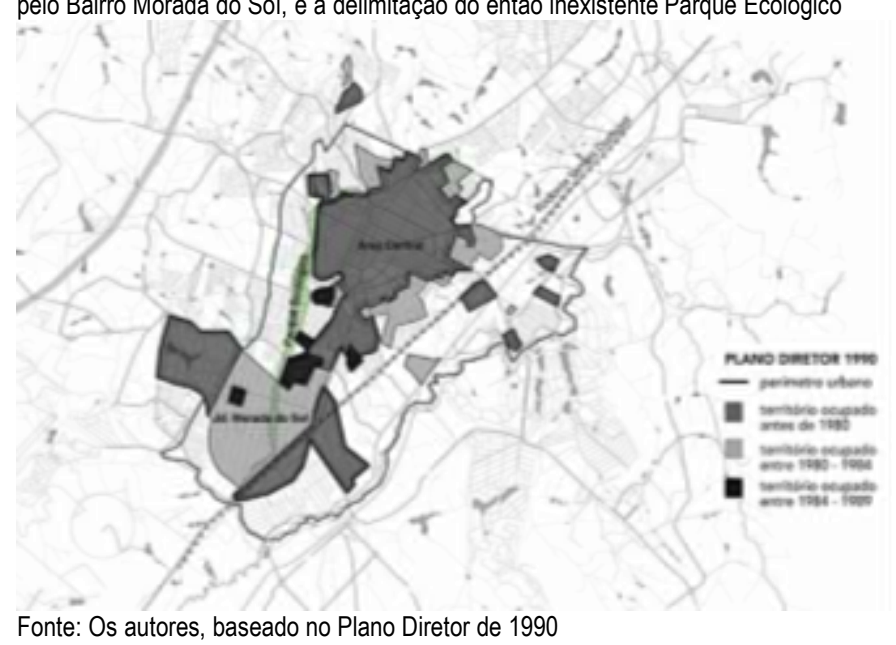

\section{Segundo Plano Diretor de Indaiatuba (1990)}

Desenvolvido pelo Arquiteto Ruy Ohtake, o plano estimava um horizonte populacional de 250 mil habitantes, muito próximo do número atual de moradores. Ohtake propôs a interligação entre a cidade antiga (zona sul) e a zona Norte através de um parque linear denominado Parque Ecológico. Essa área verde tornou-se o cartão postal e a principal estrutura de lazer do município (Figura 4). 
Neste período o zoneamento de uso e ocupação do solo da cidade não contemplava a extensão de áreas já urbanizadas. A lei de zoneamento $\mathrm{n}^{\mathrm{o}} 1.048 / 69$ e seus complementos apenas se adequavam as condições existentes e, se mostravam insuficientes para direcionar o crescimento urbano.

Figura 4 - Parque Ecológico, entre o Jardim Morada do Sol, em primeiro plano, parque das Nações, à esquerda, faceando a Rodovia SP-75 e o Distrito Industrial

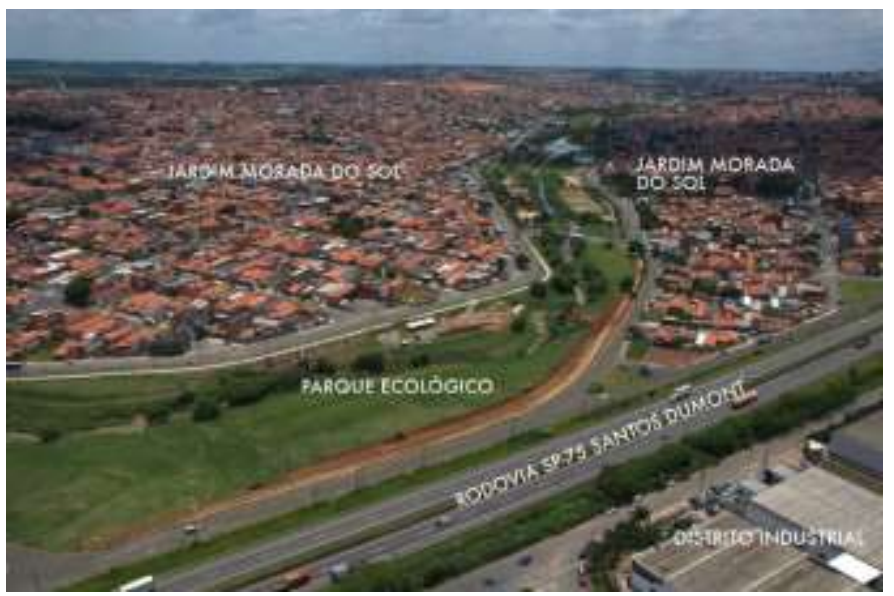

Fonte: Os autores, sobre Imagem de Eliandro Figueira - SCS/PMI

A atividade industrial continua a marcar o desenvolvimento da cidade. Em 1991, a indústria de transformação, juntamente com a indústria de construção civil, empregava $50 \%$ da mão-de-obra do município (ALVES, 2002).

No tocante ao uso habitacional, a população de renda mais alta estava localizada em loteamentos no setor norte da cidade, na malha urbana mais antiga encontravam-se os moradores de classe média e na zona sudoeste as classes de baixa renda. Dos empreendimentos habitacionais voltados para a população de baixa renda, construídos entre 1978 e o final do século XX, destacam-se o Núcleo Residencial Brigadeiro Faria Lima (1024 unidades habitacionais-UH), o Jardim Juscelino Kubitscheck (366 UH), o Conjunto Habitacional João Pioli (327 UH) e vários bairros formados a partir da tipologia lote urbanizado totalizando mais de 2400 lotes (INDAIATUBA, 1990).

O plano de Ohtake dividia a cidade em cinco macrozonas. O Parque Ecológico, margeando o Córrego Barnabé, é a principal zona de preservação ambiental deste plano.

Os grandes condomínios fechados da classe de renda alta, instalados neste período e subsequentes na cidade, foram implantados nas macrozonas de Chácaras de Recreio e de Proteção Ambiental.

\section{Terceiro Plano Diretor de Indaiatuba (2001)}

Concebido dentro dos preâmbulos do Estatuto das Cidades (Lei Federal N.10.257/2001), foi desenvolvido pelo escritório Guilherme Martins Engenharia e aprovado pela lei N. 4067/2001.

Este plano simplificou o zoneamento dividindo a cidade em 3 Áreas distintas: Urbana; de Expansão Urbana; e Rural. E propôs a consolidação de um sistema de centros composto pelo centro comercial e de serviços principal e por sub-centros urbanos secundários de modo a descentralizar as atividades e facilitar o acesso da população de menor renda.

Com relação à questão habitacional, o plano estabelecia a meta de produzir anualmente de 300 a 400 novas UH a partir de 2005, incentivando a autoconstrução e mutirões em lotes urbanizados, além de propor a criação do Fundo de Desenvolvimento Habitacional.

\section{Quarto Plano Diretor de Indaiatuba (2010)}

Aprovado pela Lei complementar N.9/2010, e desenvolvido pelo mesmo escritório de engenharia do PD anterior, o último PD de Indaiatuba é concebido segundo a imposição do Estatuto das Cidades para a revisão decenal do plano.

Comparando-se os últimos dois PD a partir da divisão territorial proposta (Figura 5), percebe-se a ampliação do perímetro urbano (cor vermelha), no plano de 2010, através da expansão da área urbana para as áreas de expansão proposta em 2001. Assim como, a diminuição das Áreas de Expansão Urbana (cor amarela) e Rural (cor verde), e locação das áreas de expansão em áreas de proteção de mananciais.

Quanto ao zoneamento, é criada a Zona Residencial de Interesse Específico (ZRIE), destinada aos programas de regularização fundiária.

O Plano de 2010 contempla áreas exclusivas para as Zonas Especiais de Interesse Social (ZEIS), e Zonas Habitacionais de Interesse Social (ZHIS) nas Zonas de Predominância Residencial (ZPR2). Esse zoneamento é destinado à implantação de empreendimentos habitacionais para a população de baixa renda e sujeito a regras específicas de parcelamento, uso e ocupação do solo. Nesse sentido, confirma-se o caráter excludente do zoneamento, consolidando o quadrante sudoeste da cidade como reduto da classe de renda mais baixa. 
Figura 5 - Comparação entre a setorização territorial de Indaiatuba proposta nos planos diretores de 2010 e 2001

2010
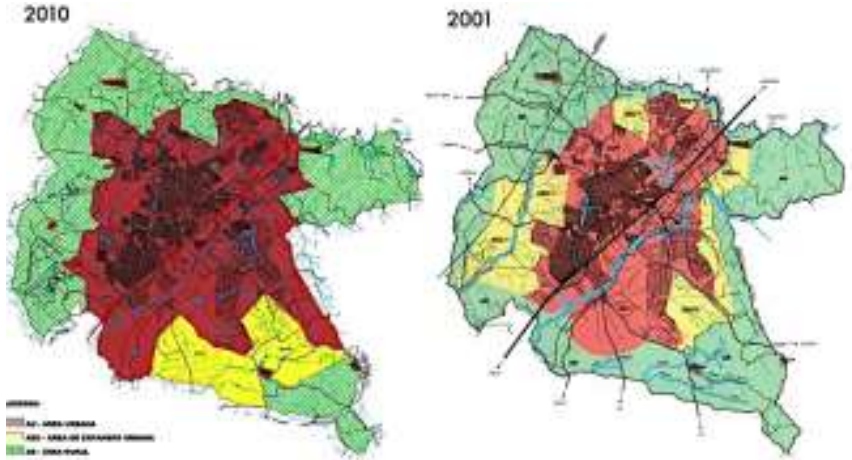

Fonte: Secretaria de Planejamento Urbano e Engenharia, Prefeitura do Município de Indaiatuba (2001, 2010)

Este plano é desenvolvido na mesma época da criação do Programa Minha Casa Minha Vida (PMCMV) que assume a maior parte da provisão de habitação de interesse social no Brasil. Segundo Nascimento e Tostes (2011), o PMCMV, como os demais planos da política habitacional, reproduz a análise isolada dos aspectos qualitativos da habitação, reduzindo o morar às unidades habitacionais, sem abordar as questões que definem a localização e suas relações com o espaço e a vida mais ampla das cidades, reproduzindo problemas crônicos e padrões perversos da urbanização brasileira.

\section{Síntese dos Planos Diretores de Indaiatuba}

Da análise dos quatro planos diretores de Indaiatuba, implantados em um período de quatro décadas, observase: a consolidação da Rodovia SP-75 como um eixo indutor de desenvolvimento; a ampliação do perímetro urbano, gerando uma configuração urbana baseada na fragmentação da mancha urbanizada; busca da transposição de obstáculos naturais (Rio Jundiaí e Córrego Barnabé) e construídos (rodovia, ferrovia, gasoduto) visando dar continuidade aos territórios contíguos; confirmação da dinâmica de territórios segregados estabelecidos pelo desenvolvimento não planejado e favorecido pelos zoneamentos dos planos diretores implementados no período.

A ampliação da área urbanizada e a diminuição de áreas de proteção ambiental produziram impactos negativos no meio ambiente, encarecendo a expansão da infraestrutura e instalação de equipamentos urbanos que afetam a qualidade de vida dos moradores, principalmente das classes mais baixas, como será apresentado adiante.

\section{Método de Pesquisa}

A investigação sobre a problemática da segregação socioespacial, definida por fatores locacionais e de acesso aos equipamentos e infraestruturas urbanas, foi realizada em três conjuntos habitacionais de interesse social, com tipologia horizontal. Foi adotada a estratégia de técnicas de Avaliação Pós-ocupação (APO), buscando destacar os níveis de satisfação dos moradores em relação aos aspectos urbanos e locacionais de seus bairros.

Couberam analisar conjuntos habitacionais de períodos distintos, dadas as diferenças contextuais e conceituais ditadas pelos planos diretores $(1968,1990,2001)$ vigentes na época que os conjuntos foram implantados.

Esta pesquisa foi orientada pelo métodos e técnicas de APO propostas por Roméro e Ornstein (2003) descritos a seguir:

(a) visitas de reconhecimento dos EHIS: realizadas de forma expedita (walkthrough) registrando as condições de uso e acesso dos equipamentos urbanos e as formas de conexão do bairro com os demais pontos da cidade, através de fotografias e conversas informais com grupos focais (6-12 moradores);

(b) entrevistas específicas com líderes comunitários: entrevistas exploratórias, com interlocutores privilegiados, visando auxiliar a elaboração do questionário;

(c) formulação e aplicação de questionário: para se obter informação sobre comportamento, atributos e atitudes dos moradores relativas a problemática investigada;

Inicialmente foram levantados dados dos projetos dos conjuntos, na Secretaria de Habitação de Indaiatuba, de forma a comparar as diretrizes urbanas propostas e as de fato implantadas.

O questionário foi estruturado em 17 questões objetivas e 2 subjetivas, considerando-se: perfil do usuário; disponibilidade de infraestrutura, serviços urbanos, equipamentos comunitários e áreas livres; proximidade dos serviços quando ausentes no bairro; conectividade; e por último a avaliação do bairro pelo morador.

Considerou-se como o universo de pesquisa o número de unidades habitacionais (UH) dos conjuntos analisados, que somam 809 unidades. O tamanho amostral foi definido por critérios de amostra aleatória simples e foram aplicados em usuários que moram há, pelo menos, um ano nas UH, e com faixa etária de 20 a 70 anos. Foram obtidas 20 aplicações válidas dos questionários para o EHIS 1, 15 para o EHIS 2 e 12 para o EHIS 3. Dessa forma, o tamanho amostral adotado foi de $47 \mathrm{UH}$. A amostra considerou pelo menos 5\% das UH em cada EHIS analisado (Tabela 2). De acordo com Roméro e Ornstein (2003), a vantagem do questionário é ser um instrumento bastante confiável, desde que as amostras sejam superiores a 30 pessoas.

Tabela 2 - Dados sobre os empreendimentos habitacionais de interesse social analisados e detalhes sobre o número de respondentes 
DEZEN-KEMPTER, Eloisa; ANHAIA, Juliana C.; TERRA, Luan O.

Questões de localização e conectividade na avaliação de qualidade urbana de habitação de interesse social em Indaiatuba

\begin{tabular}{lcccc}
\hline EHIS analisados & $\begin{array}{c}\text { Ano } \\
\text { No de } \\
\text { UH }\end{array}$ & $\begin{array}{c}\text { \% de cada EHIS no } \\
\text { universo amostral }\end{array}$ & $\begin{array}{c}\mathbf{N}^{0} \\
\text { entrevistas }\end{array}$ \\
\hline Vila Brig. Faria Lima (CECAP) $\mathbf{3}$ & 1984 & 380 & 46,97 & 20 \\
\hline João Pioli & 1996 & 327 & 40,42 & 15 \\
\hline Caminho da Luz & 2007 & 102 & 12,61 & 12 \\
\hline Total & & $\mathbf{8 0 9}$ & $\mathbf{1 0 0}$ & $\mathbf{4 7}$ \\
\hline
\end{tabular}

Fonte: Os autores

Por fim foram realizadas comparações e análises entre os resultados obtidos na APO e a fundamentação teórica (CAMPOS FILHO, 2003; CASTEL, 2005; CARDOSO, 2008; LYNCH, 1999) enfatizando questões de conectividade, localização e qualidade urbana.

\section{Estudos de Caso}

A investigação foi realizada em três EHIS - Vila Brigadeiro Faria Lima (conhecida como CECAP) fase 3, João Pioli e Caminho da Luz - implantados sob a vigência dos planos diretores de 1968, 1990 e 2001 respectivamente. Todos possuem tipologia habitacional unifamiliar térrea. A Figura 6 relaciona a implantação dos EHIS com os raios de influência da área central, e a Figura 7 exibe o desenho urbano dos três loteamentos.

O Quadro 1 sintetiza as principais características dos EHIS estudados.

\section{Resultados obtidos}

A Figura 8 apresenta as imagens das visitas de reconhecimento aos EHIS, realizadas na forma de walkthrough. Na primeira abordagem in loco foi possível identificar os espaços com maior intensidade de uso, conhecer os espaços abertos e elaborar uma avaliação subjetiva da qualidade urbana, de forma a permitir o entendimento das colocações dos moradores, no momento das entrevistas.

Com a amostra analisada, procurou-se retratar os níveis de satisfação dos moradores desde o acesso ao comércio de pequeno porte até aos serviços de âmbito urbano. Primeiramente são apresentados os resultados desta apreciação comparando-se os três EHIS analisados. Na sequência são discutidas questões de educação, saúde, comércio e serviços, segurança, mobilidade, recreação e áreas verdes a partir das inferências obtidas. Por fim um quadro compara os resultados da APO com as premissas dos Planos diretores da cidade para cada item analisado.

A Figura 9 apresenta o resultado obtido em todas as categorias analisadas por bairro.

Figura 6- Localização dos EHIS na Cidade de Indaiatuba. (1) CECAP III; (2) João Pioli; (3) Caminho da Luz; P.E. - Parque Ecológico

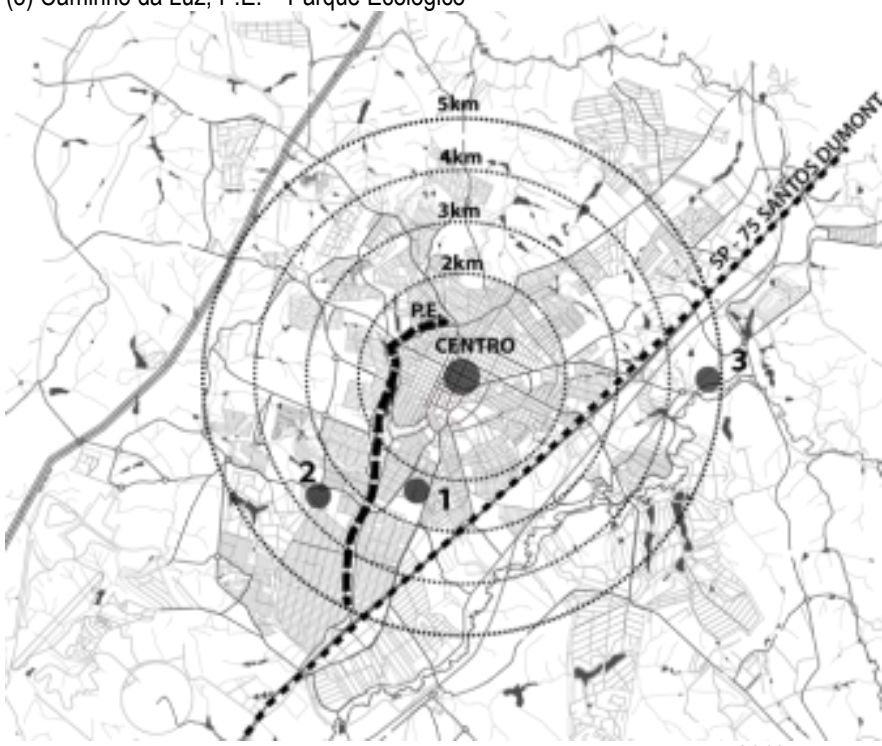

Fonte: Elaboração dos autores, sobre mapa urbano do Plano Diretor de 2010.

Figura 7 - Mapas de Implantação Geral dos EHIS: (A) CECAP fase III; (B) João Pioli; e (C) Caminho da Luz
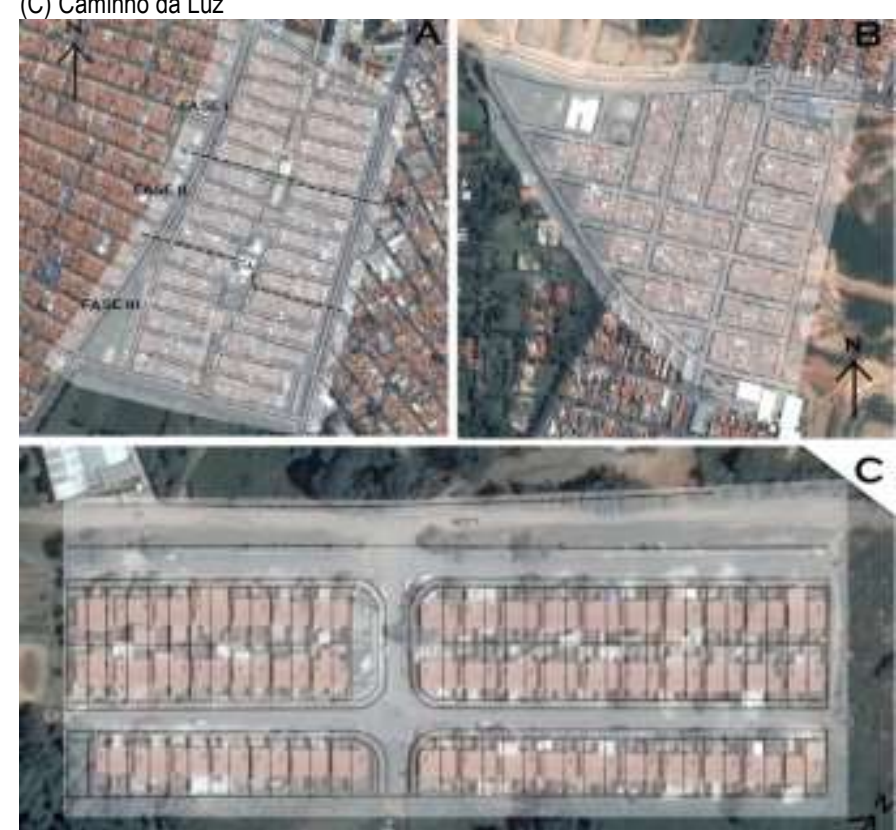

Fonte: Os autores

Quadro 3 - Características tipológicas das EHIS estudadas

\begin{tabular}{|c|c|c|c|c|c|}
\hline EHIS & $\begin{array}{l}\mathrm{N}^{\circ} \\
\text { dorm. }\end{array}$ & $\begin{array}{l}\text { Área }\left(m^{2}\right) \\
\text { habitação }\end{array}$ & $\begin{array}{c}\text { Área }\left(\mathrm{m}^{2}\right) \\
\text { lotes }\end{array}$ & $\begin{array}{c}\text { Largura } \\
\text { vias }\end{array}$ & $\begin{array}{l}\text { Largura } \\
\text { calçadas }\end{array}$ \\
\hline \multirow{2}{*}{ CECAP - fase 3} & 2 & 38,27 & \multirow{2}{*}{$160-250$} & \multirow{2}{*}{$6-7$} & \multirow{2}{*}{$2-2,5$} \\
\hline & 3 & 50,32 & & & \\
\hline \multirow{2}{*}{ João Pioli } & 1 & 33,47 & \multirow{2}{*}{$152-180$} & & \multirow[b]{2}{*}{2} \\
\hline & 2 & 43,18 & & & \\
\hline Caminho da Luz & 2 & $46,68-53,61^{[1]}$ & $145-160$ & $8-9$ & 3 \\
\hline
\end{tabular}

[1] unidades adaptadas para cadeirantes

Fonte: Os autores 
Figura 8 - Imagens dos EHIS analisados: (A) CECAP III; (B) João Pioli; (C) Caminho da Luz. Os números referem-se aos equipamentos urbanos: (1) Educação; (2) Saúde; (3) Transporte; (4) Sistema viário; (5) áreas de lazer



Fonte: Os autores

Figura 9 - Gráfico com a análise do nível de satisfação dos moradores dos Conjuntos Habitacionais CECAP III, João Pioli e Caminho da Luz

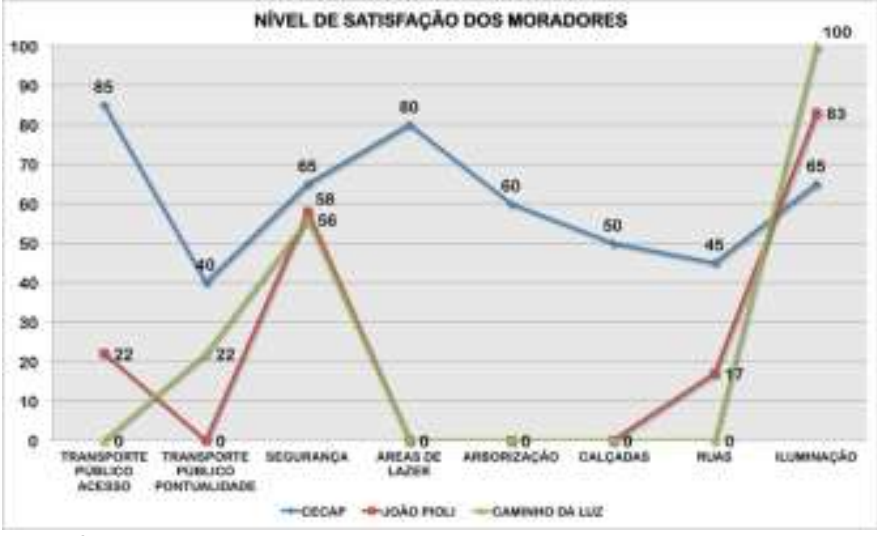

Fonte: Os autores

\section{Nível de Satisfação dos moradores com seu Bairro}

O bairro CECAP recebeu as melhores avaliações por parte dos moradores. É o bairro mais antigo e os respondentes moram no bairro, em média, há mais de 20 anos. Este bairro encontra-se inserido na malha urbana consolidada, próximo ao centro comercial do município, provido de serviços de educação, saúde, transporte e lazer. Foi criado na vigência do primeiro plano diretor e implantado em zona industrial, que foi integrada, no plano diretor de 2010, na zona de predominância residencial (ZPR) para o fim exclusivo de edificação de interesse social.

Os EHIS João Pioli e Caminho da Luz estão implantados em áreas com pouca infraestrutura urbana e apresentam os piores resultados em saúde, transporte, segurança e pavimentação. A questão locacional foi apontada pelos moradores do Caminho da Luz, bairro analisado mais distante da área central, como o maior obstáculo a ser enfrentado.

$\mathrm{O}$ único EHIS que possui área de lazer bem equipada e integrada ao bairro é o CECAP (fig.9-A5), e resultou no maior índice de avaliações positivas. Nos demais EHIS, as áreas de lazer são consideradas sem vida e desqualificadas para o uso satisfatório de modo pleno. As ruas e calçadas receberam avaliações negativas quanto à largura, manutenção e presença de barreiras físicas em todos os bairros analisados, assim como a falta de arborização.

Os resultados alcançados por esta investigação se aproximam daqueles enfatizados por Werna, Abiko e Coelho (2002) como "problemas tradicionalmente apontados" relativos à carência de áreas de lazer e segurança pessoal e patrimonial em EHIS, assim como sua inserção na malha urbana.

\section{Educação}

Os moradores foram questionados quanto à ausência/existência e proximidade dos serviços e equipamentos de educação. No quesito educação, todos os EHIS apresentam creches e escolas de ensino fundamental para as crianças e jovens. Quanto ao ensino médio, o Caminho da Luz não apresenta alternativa local para os estudantes, obrigando-os a se deslocarem para os bairros vizinhos.

A proximidade das escolas em relação à moradia é enfatizada por Campos Filho (2003) como requisito desejável para o conforto e segurança do escolar. O autor salienta ainda a relação direta entre distâncias a serem percorridas e o tempo gasto no deslocamento, assim como, os custos envolvidos no transporte e o comprometimento de amigos e familiares. Sob esta perspectiva, o bairro mais afastado da área central é o único que não oferece para a população acesso à formação escolar completa, obrigando os estudantes do ensino médio à deslocamentos $\mathrm{e}$ dependência do transporte coletivo, que como veremos no item mobilidade, também é considerado insatisfatório neste local.

\section{Saúde}

Dos EHIS analisados o CECAP III é o único próximo de hospital e de posto de saúde. O João Pioli não possui posto de saúde local, o que leva seus moradores a se deslocarem para outros bairros, motivo de grande reclamação entre os entrevistados. A Prefeitura de Indaiatuba está construindo neste bairro uma Unidade Básica de Saúde. O Caminho da Luz possui um Centro de Referência de Assistência Social (CRAS), que presta serviço médico descontinuado, gerando grande descontentamento por parte dos moradores. 
Considerando-se que o acesso aos serviços de saúde é um fator fundamental para a qualidade de vida das pessoas (IANNI; QUITÉRIO, 2006), novamente o bairro mais distante da malha urbanizada consolidada é também o que recebe os piores serviços de saúde.

Os resultados obtidos confirmam a tese de Kilsztajn e Silva (2007), que os locais onde a população mais depende dos serviços de saúde são também aqueles com serviços mais precários e escassos. O mesmo fato já havia sido destacado por Buss (1995) ao relacionar a população carente, mais exposta a riscos à saúde, e sua dificuldade de acesso aos serviços de saúde, assim como a qualidade destes serviços quando disponíveis. Portanto quanto à questão Saúde, a condição de atendimento aos moradores de EHIS não evolui muito nos últimos 20 anos, como mostram as pesquisas.

\section{Comércio e Serviços}

Para a avaliação deste item nos EHIS estudados, adotouse o nível de organização do comércio e serviços proposto por Campos Filho (2003), dividido em três níveis, onde quanto maior a demanda pelo serviço, mais próximo deverá estar da moradia:

(1) Comércio e serviço de apoio imediato à moradia (local), frequência diária ou semanal de utilização;

(2) Comércio e serviço ainda de apoio à moradia (diversificado), com frequência menor de demanda;

(3) Comércio e serviço de apoio a outras atividades urbanas, típico de centros de hierarquia superior da cidade, diversificado e coerente com o mercado para o qual é oferecido (especializado), com frequência de demanda muito menor, rara a esporádica.

O EHIS com o maior oferta de comércio e serviço é o CECAP, nele encontram-se os três níveis de organização: local, diversificado e especializado. A criação dos Corredores Comerciais no Plano Diretor de 1991 beneficiou os moradores deste bairro.

O João Pioli dispõe de comércio e serviços de nível local e diversificado, e para aqueles de frequência esporádica, os moradores deslocam-se para o bairro vizinho, o Jardim Morada do Sol, maior bairro da cidade com intensa atividade comercial.

Para os moradores do Caminho da Luz esta questão é bastante relevante, pois o bairro não possui nenhuma atividade local de comércio e serviços, levando a população a depender do transporte público ou privado para atender suas necessidades básicas.

$\mathrm{O}$ atendimento das necessidades de comércio e serviços relaciona-se principalmente em dar autonomia ao bairro, para que a procura por serviços de transporte seja menor, visto que a questão da mobilidade se apresenta como o maior problema urbano (CAMPOS FILHO, 2003).

\section{Mobilidade}

Uma das questões levantadas na APO referente à Mobilidade foi a acessibilidade ao transporte público, entendida como a maior ou menor facilidade de acesso ao sistema, que é proporcional ao tempo decorrido até o ponto de parada e o tempo de espera pelo veículo (CARDOSO, 2008).

Os moradores do CECAP consideram o bairro bem servido pelo transporte público, sendo que $85 \%$ avaliaram os pontos de ônibus como de fácil acesso, porém $60 \%$ reclamaram da falta de pontualidade e $70 \%$ consideram o tempo de espera excessivo.

No João Pioli, $78 \%$ não consideram o transporte de fácil acesso, devido à localização do ponto de ônibus, $100 \%$ relataram que o transporte não é pontual e que o tempo de espera é grande. Os respondentes relataram que problemas com as linhas são recorrentes, muitas vezes levando à interrupção do serviço.

O acesso ao ponto de ônibus é considerado fácil no Caminho da Luz, contudo $78 \%$ declararam insatisfação com relação à pontualidade e ao intervalo entre a mesma linha. Outro motivo que aborrece os passageiros é a distância com relação ao centro e a outros bairros, e a falta de linhas diretas interligando o destino, aumentando o tempo de espera e de percurso.

Esta reclamação corrobora com a afirmação de Villaça (1999), que a população urbana, especialmente a de baixa renda, é obrigada a fazer uma infinidade de deslocamentos (penosos) para atingir os destinos desejados. Essa situação compromete a conexão aos serviços básicos que definem a situação de bem-estar de uma família no local de sua moradia, como alerta Freitas (2004).

A importância da mobilidade deve ser entendida como parte da qualidade de vida almejada por todos os habitantes de uma cidade (CARDOSO, 2008). Essa questão prevalece em diversas pesquisas de APO em EHIS, como em Kowaltowski et al. (2006), que também relata as dificuldades enfrentadas pelos moradores para alcançar serviços de melhor qualidade e/ou ausentes nos EHIS analisados.

\section{Segurança}

Outro fator preponderante para avaliação da qualidade urbana nos EHIS estudados refere-se a segurança pública.

A falta de segurança foi destacada em graus diferenciados pelos moradores dos EHIS pesquisados. O CECAP apresentou índices de satisfação maior que os demais, 65\% dos entrevistados disseram haver segurança no bairro, este índice cai para 58,33\% no João Pioli e 55,56\% no 
Caminho da Luz, estes mesmos números se repetem quando indagados sobre a presença de ronda policial nos conjuntos relacionados. Em todos os EHIS os moradores elegeram a existência de tráfico e usuários de drogas como o maior motivo de insegurança e ameaça ao seu bem-estar. Os moradores sentem-se indefesos e por medo de represálias não denunciam a situação para a força policial, o que leva os usuários de drogas e traficantes a dominarem as áreas de recreação e as ruas, principalmente à noite, degradando estes locais e causando tumulto, privando os moradores da possibilidade de atividades sociais comunitárias de lazer noturnas.

Esse resultado corrobora a afirmação de Soares (2006), que o tráfico é a origem padrão das ameaças à comunidade, pois ele se instala rapidamente nas periferias exercendo domínio territorial e recrutando jovens vulneráveis.

Ainda na perspectiva da influência negativa do tráfico nos bairros, Castel (2005) coloca que os bairros considerados sensíveis reúnem os principais fatores que causam insegurança entre seus moradores (como altas taxas de desemprego, empregos precários e atividades marginais, habitat degradado, falta de urbanismo, práticas delinquentes ligadas ao tráfico de drogas e às receptações, incivilidades nos momentos de tensão, agitação e conflito com as forças policiais) o que leva a insegurança social e a insegurança civil coincidirem.

Os resultados da APO referentes à segurança remete ao que Kowaltowski et al. (2006) ressaltam sobre a relação entre a segurança física e psicológica dos moradores de conjuntos habitacionais e o uso adequado de espaços e equipamentos.

\section{Recreação e áreas verdes}

Dentre os meios para prevenir a exposição dos jovens à criminalidade, os programas recreativos de esporte, lazer e cultura exercem uma função importante.

O CECAP é o bairro que apresenta maior número de equipamentos públicos de atividades recreativas para os jovens (quadras e parques) o que refletiu no alto nível de satisfação (80\%) de seus moradores. Nos EHIS João Pioli e Caminho da Luz 100\% dos moradores estão insatisfeitos, pois as áreas apresentam quadra e parques sem vida, sem manutenção e arborização.

Esses resultados corroboram a visão de Lynch (1999) sobre a importância de locais públicos vivos para a harmonia da imagem ambiental, pois incitam as atividades de encontro e troca, facilitando a participação em atividades de grupo e favorecendo o sentimento de pertencimento, tanto com relação à comunidade quanto com à vida da cidade.

Dentro do conceito de espaços de vida pública e atividade de vizinhança, as ruas e calçadas também desempenham um papel importante.

Os três EHIS investigados apresentam larguras de vias e calçadas diferentes, e todos consideram essas características inadequadas. No CECAP a insatisfação dos moradores é cerca de 50\%, e no João Pioli e Caminho da Luz esse índice alcança $100 \%$. No último o agravante maior está no fato da principal rua de acesso ao bairro não ser asfaltada, e alagar nos períodos chuvosos, interditando o acesso para a via arterial que conecta o bairro com a cidade. $\mathrm{O}$ resultado de insatisfação relativo às ruas e calçadas pode interferir no grau de socialização entre os moradores, pois como destaca Bonduki (1998), a habitação não se restringe apenas a moradia mas estendese além dos limites do lote.

Outros fatores de insatisfação mencionados nos bairros foram a falta de arborização, a presença de barreiras físicas nas calçadas e ruas, como lixo, entulhos, irregularidades, degraus, buracos, desníveis, presença de postes e telefones públicos no meio do passeio, assim como, a ausência de rampas para cadeirantes e de sinalização para pedestres, a falta de manutenção e a má qualidade do asfalto.

A iluminação das ruas e calçadas mostrou-se satisfatória para 65\% dos entrevistados no CECAP, 83\% no João Pioli e $100 \%$ no Caminho da Luz. Nota-se a importância desta categoria de análise, pois o Caminho da Luz é isolado da malha urbana consolidada, e a iluminação constitui um elemento fundamente para garantir segurança para os moradores.

Vale salientar, como ressalta Basso (2001), que a boa manutenção dos espaços públicos de lazer promove o orgulho do morador pelo bairro e previne vandalismo, colaborando com o prestigio destas áreas e o nível de satisfação dos moradores com o lugar.

O quadro 2 compara os resultados da APO nos 3 EHIS e as diretrizes dos planos diretores relativas a cada item avaliado nesta pesquisa. 
DEZEN-KEMPTER, Eloisa; ANHAIA, Juliana C.; TERRA, Luan O.

Questões de localização e conectividade na avaliação de qualidade urbana de habitação de interesse social em Indaiatuba

\begin{tabular}{|c|c|c|c|c|}
\hline Categorias & CECAP III (1984) & João Pioli (1996) & Caminho da Luz (2007) & Diretrizes e Proposições dos Planos diretores \\
\hline Educação & $\begin{array}{l}\text { Acesso à educação } \\
\text { básica (educação infantil, } \\
\text { ensino fundamental e } \\
\text { médio) }\end{array}$ & $\begin{array}{l}\text { Acesso à educação } \\
\text { básica (educação infantil, } \\
\text { ensino fundamental e } \\
\text { médio) }\end{array}$ & $\begin{array}{l}\text { Acesso somente à } \\
\text { educação infantil e ao } \\
\text { ensino fundamental }\end{array}$ & $\begin{array}{l}\text { Tanto o CECAP quanto o João Pioli conquistaram o serviço } \\
\text { público de educação pleno, que atende as necessidades dos } \\
\text { moradores, posteriormente à sua implantação. Apesar das } \\
\text { diretrizes gerais dos últimos PD privilegiarem o cumprimento } \\
\text { das funções sociais da cidade, como estabelecido pelo } \\
\text { Estatuto da Cidade, percebe-se que os interesses e } \\
\text { necessidades dos moradores do Caminho da Luz, } \\
\text { implantado na vigência do } 3^{\circ} \mathrm{PD} \text {, relativos à educação ainda } \\
\text { não foram contemplados. }\end{array}$ \\
\hline Saúde & $\begin{array}{l}\text { Acesso à Hospital e Posto } \\
\text { de Saúde (ou Unidade } \\
\text { Básica de Saúde- UBS) }\end{array}$ & $\begin{array}{l}\text { Sem acesso imediato a } \\
\text { nenhum tipo de } \\
\text { equipamento de saúde }\end{array}$ & $\begin{array}{l}\text { Acesso somente ao } \\
\text { Centro de referência de } \\
\text { assistência social } \\
\text { (CRAS), que oferece } \\
\text { atendimento médico } \\
\text { eventual, exceto o } \\
\text { emergencial. }\end{array}$ & $\begin{array}{l}\text { No quesito saúde, questões de localização acabam } \\
\text { ganhando importância, como se pode comprovar no CECAP. } \\
\text { O PD de } 2001 \text { tinha como diretriz prover uma distribuição } \\
\text { adequada dos equipamentos de saúde, contudo as áreas } \\
\text { isoladas da malha urbana consolidada, como o Caminho da } \\
\text { Luz, não foram beneficiadas por essa diretriz. Quando da } \\
\text { realização da APO, a UBS do João Pioli estava em } \\
\text { construção e fazia parte das proposições do PD de } 2001 \text {. }\end{array}$ \\
\hline $\begin{array}{l}\text { Comércio e } \\
\text { serviços }\end{array}$ & $\begin{array}{l}\text { Acesso ao comércio local, } \\
\text { diversificado e } \\
\text { especializado }\end{array}$ & $\begin{array}{l}\text { Acesso ao comércio local } \\
\text { e diversificado. }\end{array}$ & $\begin{array}{l}\text { Sem acesso a qualquer } \\
\text { tipo de atividade } \\
\text { comercial e de serviços }\end{array}$ & $\begin{array}{l}\text { Novamente fatores locacionais privilegiam a oferta de } \\
\text { determinados serviços na cidade. O PD de } 2001 \text { estabeleceu } \\
\text { a expansão linear das atividades terciárias a partir do centro } \\
\text { comercial, ao longo dos principais corredores viários, como a } \\
\text { Avenida Francisco de Paula Leite, principal via de acesso ao } \\
\text { CECAP. Essa via foi consolidada como parte do sistema } \\
\text { radial da cidade no PD de } 2010 \text {. }\end{array}$ \\
\hline Mobilidade & $\begin{array}{l}\text { Bem conectado, } \\
\text { facilidade de acesso às } \\
\text { linhas de transporte. } \\
\text { Insatisfação relativa } \\
\text { quanto à frequência e } \\
\text { pontualidade. }\end{array}$ & $\begin{array}{l}\text { Difícil acesso ao serviço } \\
\text { de transporte. } \\
\text { Insatisfação geral quanto } \\
\text { à frequência e } \\
\text { pontualidade. }\end{array}$ & $\begin{array}{l}\text { Fácil acesso às linhas de } \\
\text { transporte. Insatisfação } \\
\text { relativa quanto à } \\
\text { frequência e } \\
\text { pontualidade. } \\
\text { Falha na integração entre } \\
\text { linhas }\end{array}$ & $\begin{array}{l}\text { Eram diretrizes dos PD de } 2001 \text { e } 2010 \text { melhorar a qualidade } \\
\text { do transporte coletivo, através da melhoria dos veículos, } \\
\text { percursos e frequência, assim como a otimização das linhas. } \\
\text { A insatisfação dos moradores dos três EHIS quanto à } \\
\text { frequência do transporte coletivo e a falta de integração entre } \\
\text { as linhas, no caso do Caminho da Luz, aponta para o não } \\
\text { cumprimento dessa diretriz. }\end{array}$ \\
\hline Segurança & $\begin{array}{l}2 / 3 \text { dos moradores } \\
\text { declararam que o bairro é } \\
\text { seguro }\end{array}$ & \begin{tabular}{|l} 
Mais de $50 \%$ dos \\
moradores declararam \\
que o bairro é seguro
\end{tabular} & $\begin{array}{l}\text { Cerca de } 50 \% \text { dos } \\
\text { moradores declararam } \\
\text { que o bairro é seguro }\end{array}$ & $\begin{array}{l}\text { Apesar do alto índice de satisfação dos moradores quanto à } \\
\text { segurança pública, os últimos PD da cidade apresentam } \\
\text { diretrizes gerais aludindo à garantia da proteção aos } \\
\text { logradouros e edifícios públicos e à colaboração entre órgãos } \\
\text { estaduais e municipais de segurança pública, sem diretrizes } \\
\text { específicas para setores distintos da cidade. }\end{array}$ \\
\hline \begin{tabular}{|c|} 
Recreação e \\
áreas \\
verdes
\end{tabular} & $\begin{array}{l}\text { Existência de espaços } \\
\text { públicos de lazer } \\
\text { considerados bem } \\
\text { cuidados e com } \\
\text { vitalidade, assim como } \\
\text { vias e calçadas } \\
\text { adequadas à integração } \\
\text { comunitária. }\end{array}$ & $\begin{array}{l}\text { Ausência de espaços } \\
\text { públicos de lazer } \\
\text { considerados bem } \\
\text { cuidados e com } \\
\text { vitalidade, assim como } \\
\text { vias e calçadas } \\
\text { adequadas à integração } \\
\text { comunitária. }\end{array}$ & $\begin{array}{l}\text { Ausência de espaços } \\
\text { públicos de lazer } \\
\text { considerados bem } \\
\text { cuidados e com } \\
\text { vitalidade, assim como } \\
\text { vias e calçadas } \\
\text { adequadas à integração } \\
\text { comunitária. }\end{array}$ & $\begin{array}{l}\text { As proposições dos PD de } 2001 \text { e } 2010 \text { relativas à } \\
\text { recreação, cultura, esporte e sistemas de lazerláreas verdes } \\
\text { concentram-se principalmente na implantação de } \\
\text { playgrounds, recantos sombreados e quadras polivalentes } \\
\text { próximas das residências. A grande reclamação dos } \\
\text { moradores é com relação à manutenção destes espaços e à } \\
\text { falta de arborização nas vias. }\end{array}$ \\
\hline
\end{tabular}

Fonte: Os autores

Ao final das entrevistas foi solicitado que os moradores atribuíssem uma nota de 0 a 10 ao seu bairro considerando seus aspectos qualitativos ambientais. O CECAP foi o mais valorizado pelos moradores e recebeu a maior nota, 8,33, o João Pioli recebeu 7,75 e o Caminho da Luz 5,67. O CECAP é o EHIS analisado mais antigo, e a distância inicial que havia entre este e a área central da cidade foi sendo minimizada pelo desenvolvimento urbano ao seu redor. Assim, o CECAP possui maior acessibilidade aos equipamentos e infraestruturas urbanas, com vantagens locacionais devido ao processo de extensão das atividades centrais e de corredores comerciais e de serviços previstos pelos planos diretores subsequentes ao seu surgimento. A falta de conectividade do Caminho da Luz com as áreas mais densamente urbanizadas da cidade é refletida na ausência de equipamentos e infraestruturas urbanas, assim como no grau de satisfação do morador. A perspectiva de melhoria dessa condição dependerá exclusivamente de políticas urbanas, o que recai na eficácia dos planos diretores.

\section{Considerações Finais}

Nesta pesquisa adotaram-se técnicas de APO e análise do desenvolvimento urbano na cidade de Indaiatuba como forma de avaliar a problemática da segregação socioespacial, definida por fatores locacionais e de acesso a equipamentos e infraestruturas urbanas, e seu impacto na 
qualidade urbana e na percepção de valor do bairro pelo morador.

Ao se analisarem os estudos de caso selecionados foi possível verificar sua coerência com o preconizado no histórico das políticas públicas voltadas para a habitação social no Brasil, como as moradias mínimas, repetitivas, de baixa qualidade arquitetônica e construtiva e distantes da área central. Nestes espaços, a moradia passa a ser concebida como uma questão meramente quantitativa e não qualitativa. Os resultados obtidos na APO confirmam essa perspectiva.

$\mathrm{O}$ estudo realizado demonstra que os resultados de APO podem ser utilizados para apoiar a proposição de diretrizes urbanas nos planos diretores, corrigindo possíveis falhas de conectividade e oferecimento de serviços e equipamentos urbanos que poderão a curto, médio e longo prazo minimizar as desvantagens locacionais de EHIS, privilegiando de fato a função social da cidade, tão enfatizada no Estatuto da Cidade.

Sobre a política de desenvolvimento urbano, pode-se concluir com um comentário de Rolnik et al. (2010) que os planos diretores não deveriam somente ditar diretrizes para o futuro da cidade, mas se preocuparem com a qualidade do que já está implantado e o que pode ser mudado para melhorar a vida das pessoas que residem nestes locais.

\section{Referências}

ABIKO, A.K.; ORNSTEIN, S.W. (ed.) Inserção Urbana e Avaliação Pós-Ocupação (APO) da Habitação de Interesse Social. São Paulo :FAUUSP, 2002. (Coletânea Habitare/FINEP, v.1).

ALVES, M. A. da S.. Município de Indaiatuba. In: CANO, W.; BRANDÃO, G. A. (Coord.). A Região metropolitana de Campinas: urbanização, economia, finanças e meio ambiente. Campinas: Editora da UNICAMP. 2002. p. 315-347.

BAENINGER, R. Região Metropolitana de Campinas: expansão e consolidação do urbano paulista. In: HOGAN, D. J. et al. (Org.). Migração e ambiente nas aglomerações urbanas. Campinas: Editora da UNICAMP: UNICAMP/NEPO, 2001. p. 321348.

BASSO, J. Investigação de fatores que afetam o desempenho e apropriação de espaços abertos públicos: o caso de Campo Grande - MS. 2001. 227 p. Dissertação (Mestrado em Arquitetura e Urbanismo) - Faculdade de Arquitetura e Urbanismo. Universidade Federal do Rio Grande do Sul, Porto Alegre, 2001. Disponível em: http://hdl.handle.net/10183/1579

BONDUKI, N. G. Origens da habitação social no Brasil. Arquitetura moderna, Lei do inquilinato e difusão da casa própria. 3. ed. São Paulo: Estação Liberdade: FAPESP, 1998. 342 p.

BRASIL, ATLAS. Atlas do Desenvolvimento Humano no Brasil. [SI]: PNUD, 2013.

BUSS, P. M. Saúde e desigualdade: O caso do Brasil. In: BUSS, P. M.; LABRA, M. E. (Org.). Sistemas de saúde: continuidades e mudanças. São Paulo/Rio de Janeiro: Editora HUCITEC/FIOCRUZ, 1995. p. 61-101.

CAIADO, M. C. S.; PIRES, M. C. S. Campinas Metropolitana: transformações na estrutura urbana atual e desafios futuros. In: GUNHA, J. M. P. (Org.). Novas metrópoles paulistas: população, vulnerabilidade e segregação. Campinas: Editora da UNICAMP: UNICAMP/NEPO, 2006. p. 275-304.

CAMPOS FILHO, C. M. Reinvente seu bairro: caminhos para você participar do planejamento de sua cidade. São Paulo, SP: Editora 34, 2003. 224 p.

CARDOSO, C. E. de P. Análise do transporte coletivo urbano sob a ótica dos riscos e carências sociais. 2008. 123 p. Tese (Doutorado em Serviço Social) - Pontifícia Universidade Católica de São Paulo, São Paulo, 2008.

CASTEL, R. A insegurança: o que é ser protegido? Tradução de L. M. E. Orth. Petrópolis, RJ: Vozes, 2005. 95 p.

CONCEIÇÃO, Priscilla Assis; IMAI, César; URBANO, Mariana Ragasi. Captura e hierarquização de requisitos do cliente de habitação de interesse social a partir da Avaliação Pós-Ocupação e da técnica de preferência declarada. Gestão \& Tecnologia de Projetos, Brasil, v. 10, n. 1, p. 83-102, ago. 2015. ISSN 1981-1543. Disponível em:

<http://www.revistas.usp.br/gestaodeprojetos/article/view/98795/100527>. Acesso em: 19 abr. 2015.

doi:http://dx.doi.org/10.11606/gtp.v10i1.98795. 
ELALI, G. A. Uma contribuição da psicologia ambiental à discussão de aspectos comportamentais da avaliação pós-ocupação.

Pós. Revista do Programa de Pós-Graduação em Arquitetura e Urbanismo da FAUUSP, [S.l.], n. 20, p. 158-169, dez. 2006.

FREITAS, E. L. H. de. Como qualificar conjuntos habitacionais populares. Brasília, DF: Caixa Econômica Federal, 2004. 196 p.

IANNI, Aurea Maria Zöllner; QUITERIO, Luiz Antonio Dias. A questão ambiental urbana no programa de saúde da família: avaliação da estratégia ambiental numa política pública de saúde. Ambient. soc., Campinas, v. 9, n. 1, p. 169-180, jun. 2006. Disponível em: http://www.scielo.br/scielo.php?script=sci_arttext\&pid=S1414-753X2006000100009\&lng=en\&nrm=iso. Acesso em: 19 abr. 2015. doi: http://dx.doi.org/10.1590/S1414-753X2006000100009.

INDAIATUBA, SP. Plano de Desenvolvimento Integrado, 1968. SD Consultoria e Planejamento/Jorge Wilheim Arquitetos Associados/Prefeitura Municipal de Indaiatuba, 1968.

Plano Diretor, 1990. Rui Ohtake Arquitetura e Urbanismo/PARCON/Prefeitura Municipal de Indaiatuba, 1990.

Plano Diretor, 2001. Guilherme Martins Engenharia/Prefeitura Municipal de Indaiatuba, 2001.

Plano Diretor, 2010. Guilherme Martins Engenharia Prefeitura Municipal de Indaiatuba, 2010.

KILSZTAJN, S.; SILVA, D. F. da. Distribuição Regional dos Serviços de Saúde no Brasil. In: ENCONTRO NACIONAL DE ESTUDOS POPULACIONAIS, 12., 2000, Caxambu. Anais... São Paulo: Associação Brasileira de Estudos Populacionais, 2000. v. 1.

KOWALTOWSKI, D. C. C. K. et al.. Analise de parâmetros de implantação de conjuntos habitacionais de interesse social: enfase nos aspectos de sustentabilidade ambiental e da qualidade de vida. In: SATTLER, Miguel; PEREIRA, Fernando Osacar Ruttkay (ed.). Construção e Meio Ambiente. Porto Alegre: ANTAC, 2006 (Coleção Habitare, v. 7), p. 128-167.

KOWALTOWSKI, D. C. C. K.; GRANJA, A. D. The concept of desired value as a stimulus for change in social housing in Brazil. Habitat International, Brasil, v. 5, n. 3, p. 435-446, jul. 2011. doi: http://dx.doi.org/10.1016/j.habitatint.2010.12.002.

LYNCH, K. A imagem da cidade. Tradução de Jefferson Luiz Camargo. São Paulo, SP: Martins Fontes, 1999. 227 p.

MEDEIROS, S. R. F. Q. de. BNH: outras perspectivas. In: CONFERÊNCIA NAGIONAL DE POLÍTICAS PÚBLICAS CONTRA A POBREZA E A DESIGUALDADE, 1., 2010, Natal. Anais...Natal: EPPUR, 2010, p. 1-15.

NASCIMENTO, Denise Morado; BRAGA, Raquel Carvalho de Queiroz. Déficit habitacional: um problema a ser resolvido ou uma lição a ser aprendida?. Risco: Revista de Pesquisa em Arquitetura e Urbanismo (Online), [S.1.], n. 9, p. 98-109, jan. 2009. ISSN 1984-4506. Disponível em: http://www.revistas.usp.br/risco/article/view/44765. Acesso em: 14 abr. 2015. doi:http://dx.doi.org/10.11606/issn.1984-4506.v0i9p98-109.

NASCIMENTO, Denise Morado; TOSTES, Simone Parrela. Programa Minha Casa Minha Vida: a (mesma) política habitacional no Brasil. Arquitextos, São Paulo, ano 12, n. 133.03, Vitruvius, jun. 2011. Disponível em: $<$ http://www.vitruvius.com.br/revistas/read/arquitextos/12.133/3936>.

ROLNIK, R.; KLINTOWITZ, D.; REIS, J.; BISCHOF, R. Como produzir moradia bem localizada com recursos do programa minha casa minha vida? Implementando os instrumentos do Estatuto da Cidade. Brasília: Ministério das Cidades, 2010

ROLNIK, R.; NAKANO, K. As armadilhas do pacote habitacional. Le Monde Diplomatique, São Paulo, ano 2, n. 20, mar. 2009. Disponível em: http://www.diplomatique.org.br/artigo.php?id=461

ROMÉRO, M.A.; ORNSTEIN. S.W. (edit./coord.). Avaliação Pós-Ocupação: métodos e técnicas aplicados à habitação social. Porto Alegre: ANTAC, 2003. 294p. (Coleção Habitate)

SABOYA, R. Concepção de um sistema de suporte à elaboração de planos diretores participativos. 2007. Tese (Doutorado em Engenharia Civil) - Faculdade de Engenharia Civil, Universidade Federal de Santa Catarina, Florianópolis, 2007. 
SOARES, Luiz Eduardo. Segurança pública: presente e futuro. Estud. av., São Paulo, v. 20, n. 56, p. 91-106, abr. 2006 - Disponível em: http://www.scielo.br/scielo.php?script=sci_arttext\&pid=S0103-40142006000100008\&lng=en\&nrm=iso. Acesso em: 14 abr. 2015. doi: http://dx.doi.org/10.1590/S0103-40142006000100008.

VILLAÇA, F. J. M. Dilemas do Plano Diretor. In: CEPAM, Fundação Prefeito Faria Lima. O município no século XXI: cenários e perspectivas. São Paulo, SP: Editora: CEPAM \& CORREIOS, 1999, p. 237-248.

WERNA, E. et al. Pluralismo na habitação (baseado nos resultados do Projeto "O novo papel do Estado na oferta de habitação: parceria entre agentes públicos e não-públicos”: convênio 63.96.0737.00 - Finep) São Paulo: Annablume, 2001.

WERNA, E.; ABIKO, A.; COELHO, L. O novo papel do estado na oferta de habitação e parcerias de agentes públicos e privados. In: ABIKO, A.K.; ORNSTEIN, S.W. (Eds.), Inserção urbana e avaliação pós ocupação (APO) da habitação de interesse social. São Paulo: FAUUSP,2002. (Coletânea Habitare/FINEP, v. 1.), 373 p.

\section{${ }^{1}$ Eloisa Dezen-Kempter}

Arquiteta e Urbanista. Doutorado em História. Pós-Doutorado na University of Southern California, EUA. Endereço postal: R. Paschoal Marmo, 1888, Limeira, SP, Brasil, 13484-332

\section{Juliana Camargo Anhaia}

Tecnólogo em Construção Civil. Graduado. Endereço postal: R. Paschoal Marmo, 1888, Limeira, SP, Brasil, 13484-332

\section{${ }^{3}$ Luan de Oliveira Terra}

Tecnólogo em Construção Civil. Graduado. Endereço postal: R. Paschoal Marmo, 1888, Limeira, SP, Brasil, $13484-332$ 